\title{
Analysis of chloroplast ribosomal subunit S16 (rpS16) intron sequences in Morus (Urticales: Moraceae)
}

\author{
Wang Yuhua ${ }^{1}$, Wang Wei ${ }^{1,2}$, Tong Wei ${ }^{1}$ and Zhao Weiguo ${ }^{1 *}$ \\ ${ }^{1}$ Sericultural Research Institute, Chinese Academy of Agricultural Sciences, Jiangsu University of Science and \\ technology, Zhenjiang Jiangsu 212018, China. \\ ${ }^{2}$ School of Life Sciences, Nanjing University, Nanjing Jiangsu 210093, China.
}

Accepted 17 October, 2011

\begin{abstract}
In this study, the chloroplast rps16 sequence variation of Morus was examined. Sequence data were obtained from 18 mulberry individuals belonging to 13 species and three varieties, and two accessions of Broussonetia papyrifera and Ficus carica of the related Moraceae, designed as outgroup were analyzed. The nucleotide diversity $(0.016 \pm 0.006)$ covered 113 polymorphic sites of which 22 were parsimony informative. A total of $\mathbf{2 0}$ haplotypes were identified, producing a high overall haplotypic diversity $(1.00 \pm 0.02)$. Inferred phylogenetic relationship using the neighbor-joining method indicated genus Morus was a monophyletic and phylogenetic relationship among 18 mulberry materials was further determined. The result from cluster analysis indicates that they are basically consistent with the morphological classification.
\end{abstract}

Keywords: Mulberry, Phylogeny, rps 16.

\section{INTRODUCTION}

Mulberry (Morus L.; Family Moraceae) is a perennial and economically important plant in the sericulture industry and has traditionally been used for feeding the monophagous silkworm, Bombyx mori L. Furthermore, being a perennial tree crop with a crop cycle of over 50 years, mulberry offers additional benefits such as conservation of soil and water, enhancement of biodiversity by providing shelter to shade loving plants, and food to birds and small animals. Mulberry has a long cultivation history and is widely distributed in China, India, Bangladesh, Pakistan, and several other Asian countries. Mulberry (Morus) is believed to have originated in the northern hemisphere, particularly in the Himalayan foothills, and spread to the tropics of southern hemisphere (Benavides et al., 1994; Hou, 1994). While reviewing the centers of origin of crop plants, Vavilov (1951) placed Morus L. in China-Japan

*Corresponding author. E-mail: wgzsri@126.com. Tel: +86051185616570 . Fax: +86-051185628183.

Abbreviations: rps16, ribosomal subunit S16; RAPD, random amplified polymorphic DNA. center of plant origin. Most of the contemporary molecular studies also revealed an early diversification of Moraceae in Eurasia and subsequent migration into the southern hemisphere (Zerega et al., 2005).

Taxonomy of the genus Morus was started by Linneaus (1753) by recognizing seven species based on morphological characteristics; considerable differences exist among systematists as to the number of species that exist in this genus (Koidzumi, 1917, 1923; Hotta, 1958; Katsumata, 1972; Airy, 1973). So far, more than 150 species of mulberry have been cited in the Index Kewensis, but a majority of them have been treated either as synonyms or as varieties rather than species, and some have been transferred to allied genera. It is remarkable that Morus is the only genus of the Moraceae that has not been revised yet (Berg, 2001). Nonetheless, species of mulberry have now been widely recognized and majority of them are found in Asia, especially in China, Japan, Korea, and India (Datta, 2000). However, it is important to note that most of these species undergo natural cross hybridization and produce fertile hybrids (Dwivedi et al., 1989; Tikader and Dandin, 2001). Moreover, most of the putative mulberry species are dioecious and can cross-pollinate among 
Table 1. Information of 20 accessions used in this study

\begin{tabular}{clllc}
\hline Number & Species & Accession & Origin & $\begin{array}{c}\text { GeneBank } \\
\text { accession number }\end{array}$ \\
\hline 1 & M.atropurea Roxb. & Lunjiao 40 & Shunde city, Guangdong province, China & EF687665 \\
2 & M.cathayana Hemsl. & Baojing 5 & Baoqing city, Hunan province, China & EF687666 \\
3 & M.alba var. venose Delile. & Wenqisang & Zhouzhi city, Shanxi province, China & EF687668 \\
4 & M.mizuho Hotta. & Housang & Yuhang city, Zhejiang province, China & EF687669 \\
5 & M.alba Linn. & Niuersang & Yangcheng city, Shanxi province, China & EF687670 \\
6 & M.atropurea Roxb. & Qiner & Shunde city, Guangdong province, China & EF687671 \\
7 & M.wittiorum Hand-Mazz. & Qianesang 1 & Dejiang city, Guizhou province, China & EF687673 \\
8 & M.nigra Linn. & Yaosang & Xingjiang autonomous region, China & EF687674 \\
9 & M.mongolica Schneid. & Jimengsang & Jilin province, China & EF687675 \\
10 & M.rotundiloba Koidz. & T12 & Thailand & EF687676 \\
11 & M.mongolica var.diabolica Koidz. & Youmaoyansang & Guizhou province, China & EF687677 \\
12 & M.Laevigata Wall. & Dejiang 10 & Dejiang city, Guizhou province, China & EF687678 \\
13 & M.alba var. macrophlla Loud. & Gongxianheiyou & Gongxian city, Sichuan province, China & EF687679 \\
14 & M.bombycis Koidz & Changnongshan & Shandong province, China & EF687680 \\
15 & M.Australis Poir. & Chasang & Sichuan province, China & EF687681 \\
16 & M.alba Linn. & Sanglian & Fujian province, China & EF687682 \\
17 & M.alba var. pendula Dipp. & Chuizhisang & Korea & EF687667 \\
18 & M. multicaulis Pree. & Husang32 & Zhenjiang city, Jiangsu province, China & EF687683 \\
& & & & \\
Outgroup & Broussonetia papyrifera L. & Goushu & Zhenjiang city, Jiangsu province, China & EF687672 \\
19 & Ficus carica Linn. & Wuhuaguo & Zhenjiang city, Jiangsu province, China & EF687684 \\
\hline
\end{tabular}

All mulberry materials sampled were from National mulberry Genbank in the Sericultural Research Institute, CAAS, Zhenjiang, Jiangsu Province, China.

themselves to produce fertile hybrids, suggesting that they have relatively close genetic relationships. Such a high degree of cross-species repro-ductive success is not encountered often in nature, and thus, their "species" status needs to be investigated further (Wang and Tanksley, 1989). Another reason for this paucity of information on the general taxonomy of Morus is that most of the recent investigations were confined only to the sericulturally important species. Therefore, information on other species and their relationships with these species remains very scanty (Dandin, 1998; Zhao et al., 2006).

Molecular methods, including deoxyribonucleic acid (DNA) sequence analysis, have wide application in solution of controversial phylogenetic and taxonomic problems. Plant molecular systematics studies often refer to polymorphisms in organelles DNA sequence and in the first place chloroplast DNA (cpDNA) (Sang et al., 1997; Gielly and Taberlet, 1994; Hanilton et al., 2003). The ribosomal subunit S16 (rps16) intron was chosen because the marker has proven useful for inferring phylogenetic relationships at generic or higher levels (Andersson and Rova, 1999; Bremer and Manen, 2000; Nie et al., 2005; Abbasi et al., 2010). For the first time, the gene for the small rps16, containing a group II intron was used by Oxelman et al. (1997) and then frequently has been applied to molecular phylogeny studies of various plant taxa.

Earlier, the nucleotide variability including ITS, cpDNA trnL-F and trn L intron in Morus was determined (Zhao et al., 2004, 2005; Wang et al., 2008). However, because of ambiguous results, additional studies are still needed including intraspecies diversity analyses. The aim of this work was to evaluate rps16 intron variability for clarification of Morus phylogenetic relationship at different taxonomic levels.

\section{MATERIALS AND METHODS}

\section{Materials}

18 accessions representing 11 species and three varieties of genus Morus and two accessions of Broussonetia papyrifera and Ficus carica Linn. of the related Moraceae, designated as outgroup species were included in this study. All mulberry specimens were deposited in the National Mulberry Genbank of the Sericultural Research Institute, Chinese Academy of Agricultural Sciences (CAAS), Zhenjiang, Jiangsu province, China (Table 1).

DNA extraction, polymerase chain reaction (PCR) amplification and sequencing

Total genomic DNA was extracted from $2 \mathrm{~g}$ of fresh leaves of 


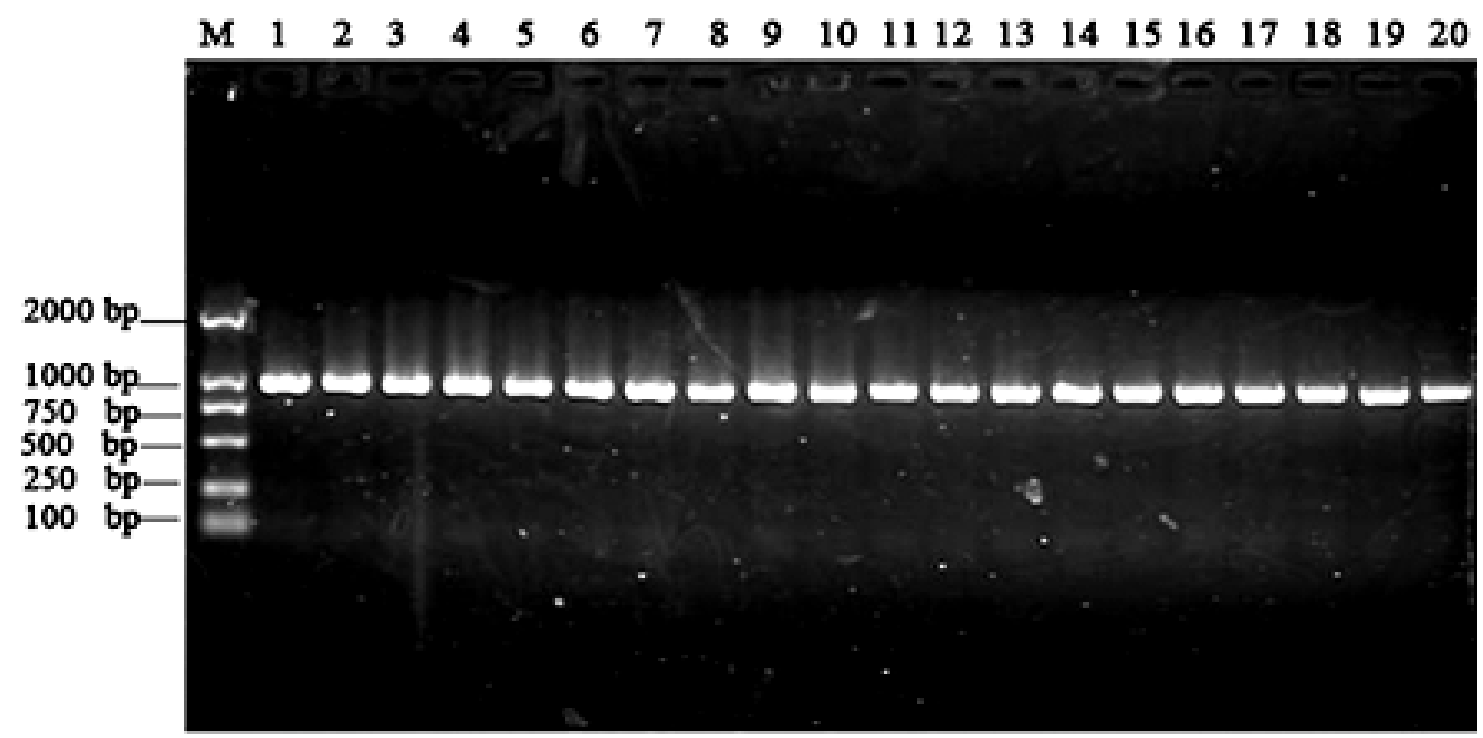

Figure 1. Electrophoretic pattern amplified in 20 materials. Lane 1-20 represents accessions, as shown in Table 1. $M$ is a DNA marker DL 2,000 (MBI).

mulberry using the CTAB method (Zhao and Pan 2004). PCR amplification were performed with universal primers for rps16 $\left(5^{\prime}\right.$ AAACGATGTGGTAGAAAGCAAC-3") and " $f$ " (5'-AACATCAATTGCAACGATTCGAT A-3') (Oxelman et al., 1997). PCR amplification was conducted in a $25 \mu \mathrm{l}$ volume containing $2.5 \mathrm{mM} \mathrm{MgCl}_{2}, 200 \mu \mathrm{M}$ of each dNTP, $5 \mathrm{pM}$ of each primer, $1.5 \mathrm{U}$ of Taq DNA polymerase (Takara Bio Inc.), 10 x PCR Buffer (100mM Tris-HCl pH 8.3, 500mM $\mathrm{KCl}, 0.01 \%$ gelatin), and approximately $25 \mathrm{ng}$ DNA template. Amplification reaction was carried out with following thermal cycles profiles: 1 cycle for $5 \mathrm{~min}$ at $95^{\circ} \mathrm{C}$ then 25 cycles of $30 \mathrm{~s}$ at $95^{\circ} \mathrm{C}, 30$ $\mathrm{s}$ at $58^{\circ} \mathrm{C}, 1 \mathrm{~min}$ at $72^{\circ} \mathrm{C}$ followed by a final extension of $7 \mathrm{~min}$ at $72^{\circ} \mathrm{C}$. The fragment amplified was purified, ligated into the clone vector and transformed into the E. coli competent cells. Finally, the recombinant fragment was sequenced by Sangon (Shanghai, China).

\section{Data analysis}

Sequence alignments were conducted using the Clustal $X$, version 1.81 (Thompson et al., 1997) and finally adjusted manually where necessary. The insertion/deletion mutations (indels) of unambiguous alignment were recoded as separate characters appended in the matrix. The data matrices are available upon request from the authors. The aligned sequences were analyzed for diversity using DnaSP version 5.0 (Librado, P. and Rozas, 2009). Two estimates of diversity, $\pi$ and $\theta$, were calculated. $\pi$ is the average number of nucleotide differences per site between two sequences and $\theta$ per site is derived from the total number of mutations (Eta) and corrected for sample size ( Rozas et al., 2003). The phylogenetic tree was constructed by MEGA4.0 using the neighbor-joining method (Tamura et al., 2007).

\section{RESULTS AND DISCUSSION}

PCR amplification with primers proposed by Oxelman et al. (1997) yielded fragments of predicted length (about $1 \mathrm{~kb}$ ) in all samples (Figure 1). Sequences of rps 16 were deposited in the GenBank database under the accession numbers EF687665-EF687684. The rpS16 intron amplicons vary in length from 938 bp in F. carica to 973 bp in Morus. The average nucleotide composition of all sequences was $36.1 \% \mathrm{~A}, 31.3 \% \mathrm{~T}, 14.2 \% \mathrm{G}$ and $18.4 \% \mathrm{C}$ and the average nucleotide content of $A+T(67.4 \%)$ was obviously higher than that of $\mathrm{G}+\mathrm{C}(40.44 \%)$, indicating that they are AT-rich. These data are in agreement with nucleotide compositions of the rpS16 intron in other plant taxa (Andersson and Rova, 1999; Lee and Hymowitz, 2001).

The results obtained by using DNAsp 5.0 (Librado, P. and Rozas, 2009) revealed a low mean nucleotide diversity $(\pi)(0.016 \pm 0.006)$ covering 113 polymorphic sites $(11.3 \%$ of the whole alignment) of which 22 were parsimony informative. A total of 20 haplotypes (excluding sites with gaps and missing data) were identified, producing high overall haplotypic diversity $(1.00 \pm 0.02)$. Theta $(\theta)$ (per site) from Eta was 0.03604, the total number of mutations was 117 , while the total number of InDel sites was 85 .

Sequence alignment revealed that all the nucleotide sequences above appear to be rather conserved. The identity between these sequences varies in a range from 93.0 to100 \%, while the average identity between all mulberry accessions sequence was above $99 \%$, with a range from 95.1 to $100 \%$. In addition, the identity between mulberry accessions and genus $F$. carica sequence was below $94.0 \%$ while the identity between mulberry accessions and genus $B$. papyrifera sequence was below $95.0 \%$. The result shows that mulberry accessions had higher genetic similarity than genus $B$. papyrifera and $F$. carica.

Molecular phylogenetic analysis was done using rpS16 


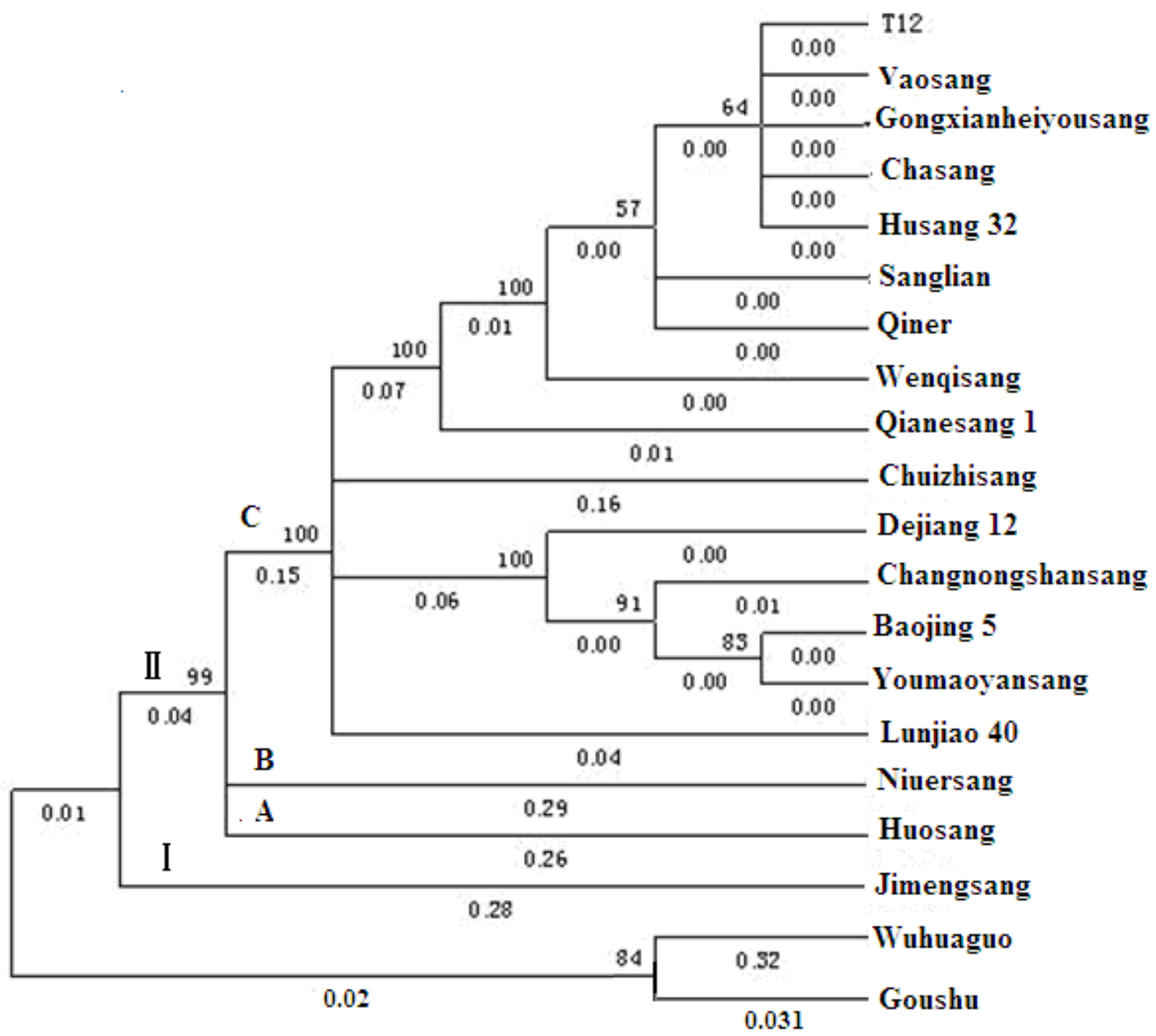

Figure 2. Phylogenetic trees obtained from the analysis of rps 16 data through the neighbor-joining method.

sequence data through the neighbor-joining method (Figure 2). The clustering result show that all species of genus Morus were grouped together, which indicated that the genus Morus was a monophyletic. The above result obtained from DNA sequences was in consistent with previous research based on the study on ITS, trnL-F and trnL intron sequences, isozymes and random amplified polymorphic DNA (RAPD) marker (Hirano, 1982; Zhao et al., 2004; Zhao and Pan, 2004; Zhao et al., 2005; Wang et al., 2008). In the genus Morus clade, Jimengsang was generally the most distant varieties in comparison with other mulberry varieties clustered into cluster I group; other mulberry cultivars were clustered into cluster II group. The above result is consistent with previous research based on the study on ITS and trnL intron sequences (Zhao et al., 2004; Wang et al., 2008). The cluster II was divided into three subgroups: A, B, and C cluster groups. Niuersang and Huosang formed independently the A and B subgroups, respectively. In C subgroup, Dejiang 12, Changnongshansang, Baojing 5 and Youmaoyansang were grouped together, indicating their closer relationship. T12, Yaosang, Gongxianheiyousang, Chasang and Husang 32 were grouped together with above $99.0 \%$ sequence similarity, indicating a closer relationship. The results from cluster analysis were basically in agreement with the existing morphologic classification. This study also indicate that phylogenetic analysis using cpDNA trnL-F intergenic spacer region sequence data offer a reliable and an efficient method of assessing phylogenetic relationship but more definitive resolution of the problems existing in mulberry classification may require utilization of results from additional studies using nuclear along with extra-nuclear informative data in future.

\section{Conclusion}

The phylogeny of genus Morus inferred from rps 16 sequences is congruent with our current understanding of 
the group. These DNA regions offer a reliable and an efficient method of assessing phylogenetic relationship at the interspecific and intergeneric levels in mulberry. It is also helpful for the conservation and identification of mulberry collections, and in mulberry breeding.

\section{ACKNOWLEDGMENTS}

We thank the anonymous reviewers and the editor for critically reviewing the manuscript. This work was support by China (20060400926), Jiangsu (0602004C) Postdoctoral Science Foundation Project, and Public Industry (Agriculture) Specific Research Program (nyhyzx07-020), and the sericulture industry technology in China program (nycytx-27-gw303).

\section{REFERENCES}

Abbasi FM, Ahmad H, Perveen F, Inamullah, Sajid M, Brar DS (2010). Assesment of genomic relationship between Oryza sativa and Oryza australiensis. Afr. J. Biotechnol. 9: 1312-1316.

Airy Shaw HK (1973). A dictionary of flowering plants and ferns, 8th edition. Cambridge University Press, London, UK.

Andersson CL, Rova JHE (1999). The rpS16 intron and the phylogeny of the Rubioideae (Rubiaceae). Plant Syst. Evol. 214: 161-186.

Benavides JE, Lachaux M, Fuentes M (1994). Efecto de la aplicacio'n de estiércol de cabra en el suelo sobre la calidad y producción de biomasa de Morera (Morus sp.). In: Bena- vides JE (ed) Arboles y arbustos forrajeros en América Central, vol II. CATIE, Turrialba. Costa Rica. pp. 495-514.

Berg CC (2001). Moreae, Artocarpeae, and Dorstenia (Moraceae). Flora Neotropica. Monograph 83. New York Botanical Garden, Bronx, NY, USA. pp. 24-32.

Bremer B, Manen JF (2000). Phylogeny and classification of the subfamily Rubioideae (Rubiaceae). Plant Syst. Evol. 225: 46-72.

Dandin SB (1998). Mulberry a versatile biosource in the service of mankind. Acta Sericol. Sin. 24: 109-113.

Datta RK (2000). Mulberry cultivation and utilization in India. FAO Electronic conference on mulberry for animal production (Morus $\mathrm{L}$ ). http://www.fao.org/DOCREP/005/ X9895E/x9895e04.htm\#TopOfPage.

Dwivedi NK, Suryanarayana N, Susheelamma BN, Sikdar AK, Jolly MS (1989). Interspecific hybridization studies in mulberry. Sericologia, 29: 147-149.

Gielly L, Taberlet P (1994). The use of chloroplast DNA to resolve plant phylogenies: noncoding versus $r b c L$ sequences. Mol. Biol. Evol. 11: 769-777.

Hamilton MB, Braverman JM, Soria-Hernanz DF (2003). Patterns and relative rates of nucleotide and insertion/deletion evolution at six chloroplast intergenic regions in New World species of the Lecythidaceae. Mol. Biol. Evol. 20: 1710-1721.

Hirano H (1982). Thremmatological studies of protein variation in mulberry. Bull. Imp. Sericult. Exp. Stat. 28: 67-186.

Hotta T (1958). Taxonomical studies on the Morus plants and their distributions in Japan and its viscinties. Japanese Society for Promotion of Science, Ueno Park, Tokyo. pp. 1-161.

Hou YJ (1994). Mulberry breeding. Zhejiang Agriculture University, Hangzhou, China. p. 4.

Katsumata $T$ (1972). Mulberry species in west Jawa and their peculiarities. J. Seric. Sci. Jpn. 42: 213-223.
Koidzumi G (1917). Taxonomical discussion on Morus plants. Bull. Imp. Sericult. Exp. Stat. 3: 1-62.

Koidzumi G (1923). Synopsis specierum generis Mori. Bull. Imp. Sericult. Exp. Stat. 11:1-50.

Lee J, Hymowitz T (2001). A molecular phylogenetic study of subtribe Glycininae (Leguminosae) derived from the chloroplast DNA rps16 intron sequences. Am. J. Bot. 88: 2064-2073.

Librado P, Rozas J (2009). DnaSP v5: A software for comprehensive analysis of DNA polymorphism data. Bioinformatics, 25: 1451-1452.

Linnaeus C (1753). Species Plantarum, Stockholm. 2: 9-86.

Nie ZL, Wen J, Sun H, Bartholomew B (2005). Monophyly of Kelloggia Torrey ex Benth. (Rubiaceae) and evolution of its intercontinental disjunction between westernnorth America and eastern Asia. Am. J. Bot. 92: 642-652.

Oxelman B, Liden M, Berglund D (1997). Chloroplast rps 16 intron phylogeny of the tribe Sileneae (Caryophyllaceae). Plant Syst. Evol. 206: 393-410.

Rozas J, Sánchez-DelBarrio JC, Messeguer X, Rozas R (2003). DnaSP, DNA polymorphism analyses by the coalescent and other methods. Bioinformatics, 19: 2496-2497.

Sang T, Crawford DJ, Stuessy TF (1997). Chloroplast DNA phylogeny, reticulate evolution, and biogeography of Paeonia (Paeoniaceae). Am. J. Bot. 84: 120-1136.

Tamura K, Dudley J, Nei M, Kumar S (2007). MEGA 4: molecular evolutionary genetics analysis (MEGA) software version 4.0. Mol. Biol. Evol. 24: 1596-1599.

Thompson J D, Gibson TJ, Plewniak F, Jeanmougin F, Higgins DG (1997). The Clustal-X windows interface flexible strategies for multiple sequence alignment aided by quality analysis tools. Nucliec Acids Res. 25: 4876-4882.

Tikader A, Dandin SB (2001). Breeding behaviour of some wild mulberry. Indian Silk. 40: 9-10. Vavilov NI (1951). The origin, immunity and breeding of cultivated plants. Chron. Bot. p.13.

Wang W, Wang X, Zhu Y, Wang S, Zhang L, Pan Y, Shen X, Yang Y, Zhao W (2008). Phylogenetic analysis of genus Morus (Urticales: Moraceae) using nucleotide sequences from the trnL Intron. Acta Sericol. Sin. 34: 298-303.

Wang ZY, Tanksley SD (1989). Restriction fragment length polymorphism in Oryza sativa L. Genome, 32: 1113-1117.

Zerega NJC, Clement WL, Datwyler SL, Weiblen GD (2005). Biogeography and divergence times in the mulberry family (Moraceae). Mol. Phylogenet. Evol. 37: 402-416.

Zhao W, Pan Y (2004). Genetic diversity of genus Morus revealed by RAPD markers in China. Int. J. Agr. Biol. 6: 950-954.

Zhao W, Pan Y, Zhang Z, Jia S, Miao Xa, Huang Y (2005). Phylogeny of the genus Morus (Urticales: Moraceae) inferred from ITS and trnL-F sequences. Afr. J. Biotechnol. 4: 563-569.

Zhao W, PanY, Zhang Z (2004). Phylogenetic relationship of genus Morus by ITS sequence data. Acta Sericol. Sin. 30: 11-14.

Zhao W, Zhou Z, Miao X, Pan Y, Huang Y (2006). Genetic relatedness among cultivated and wild mulberry (Moraceae: Morus) as revealed by inter-simple sequence repeat (ISSR) analysis in China. Can. J. Plant Sci. 86: 251-257. 